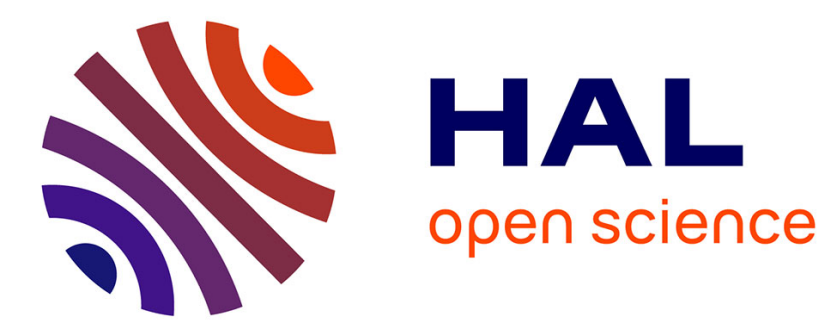

\title{
Recent advances in heat transfer to helium 1 \\ C. Johannes
}

\section{To cite this version:}

C. Johannes. Recent advances in heat transfer to helium 1. Revue de Physique Appliquée, 1971, 6 (4), pp.509-513. 10.1051/rphysap:0197100604050900 - jpa-00243579

\section{HAL Id: jpa-00243579 https://hal.science/jpa-00243579}

Submitted on 1 Jan 1971

HAL is a multi-disciplinary open access archive for the deposit and dissemination of scientific research documents, whether they are published or not. The documents may come from teaching and research institutions in France or abroad, or from public or private research centers.
L'archive ouverte pluridisciplinaire HAL, est destinée au dépôt et à la diffusion de documents scientifiques de niveau recherche, publiés ou non, émanant des établissements d'enseignement et de recherche français ou étrangers, des laboratoires publics ou privés. 


\title{
RECENT ADVANCES IN HEAT TRANSFER TO HELIUM 1
}

\author{
C. JOHANNES \\ Service de Recherches Appliquées, L'Air Liquide. \\ Centre d'Etudes Cryogéniques, Sassenage
}

\begin{abstract}
Résumé. - Les conditions d'échanges thermiques dans l'hélium 1 sont passées en revue. Ebullition libre, ébullition en thermosiphon, convection forcée. Relations entre le flux critique d'ébullition nucléée et différents paramètres. Utilisation d'hélium hypercritique.

Abstract. - Conditions of thermal exchange in helium 1 are reviewed. Pool boiling thermosiphon boiling, forced convection heat transfer. Relations between critical nucleate flux and some parameters are given. Use of hypercritical helium.
\end{abstract}

Introduction. - Most superconducting materials used in the world today are utilized at temperatures varying from 1,8 to $5 \circ$. Helium is the only working fluid that can be used as refrigerant to maintain the temperature of these materials constant. The designer of superconducting devices such as magnets and cryocables is often confronted with the problem of calculating the heat transfer from the helium to the superconducting material. In the range of temperatures used, the helium could be in the liquid, gaseous, supercritical or superfluid state. It is therefore important to know the laws governing heat transfer to helium in all its states.

Smith [1] has recently presented a review of heat transfer to helium 1. Since his review more complete data have become available. This paper is a summary of the most recent advances in heat transfer to helium 1.

The modes of heat transfer encountered in heat transfer to helium 1 are the following :

1. Pool boiling.

2. Forced convection boiling.

3. Forced convection heat transfer near the critical region.

1. Pool boiling. - Pool boiling is encountered when a superconducting device immersed in a pool of liquid helium is maintained at constant temperature by the evaporation of the liquid. Heat transfer

Nota : La brutale disparition de l'auteur, peu avant la tenue du Colloque, ne nous a pas permis de modifier le présent texte, déjà publié à Berlin en 1970 à la «Third International Cryogenic Engineering Conference ", avec une diffusion assez restreinte. Etant donné l'importance et la généralité des résultats obtenus, le Comité d'Organisation a tenu à publier ce véritable testament scientifique et technique. coefficients are generally high when the temperature difference between the device and the liquid helium is small $\left(<1^{\circ} \mathrm{K}\right)$.

Pool boiling heat transfer data are usually presented in a plot of heat flux vs. temperature difference on logarithmic coordinates as shown in figure 1 . This figure presents the data of Lyon [2], Cummings [3] and Thibault [4] obtained at $s$ pressure of 1 atm. The pool boiling data obtained at 0,5 atm are presented by Smith [1].

Figure 1 clearly indicates two stable boiling regions separated by a region of unstable boiling. The two regions are known as the nucleate boiling region and the film boiling region.

1. 1 NUClEAte BOILING. - In the nucleate boiling region the heat flux is some power function of the temperature difference :

$$
\Phi=A(\Delta \mathrm{T})^{n}
$$

where $A$ et $n$ are constants, depending on the surface properties (e.g. roughness, orientation) and the geometry. Cummings [3] has found $A=1,32$ and $n=1,4$ for horizontal copper surfaces.

Our own data [5] and those of Thibault [4] show clearly a break in the curve of $\Phi$ vs. $\Delta T$ indicating two values for $n$ (equation 1): at low heat fluxes $\left(<0,3 \mathrm{~W} / \mathrm{cm}^{2}\right)$ a value of $n$ of about 1,8 and at higher heat fluxes a value of 3 to 5 . These data have been obtained on vertical surfaces with heated lenghts of 5 to $10 \mathrm{~cm}$ and indicate the influence of convection due to the thermosiphon action of the rising bubbles as has been observed for non-cryogenic fluids.

There exists a large number of empirical equations relating the heat flux and the temperature difference [6]. The equation of Kutateladze [7] has been recommended by Brentari [8] for cryogens. This equation agrees quite well with the experimental data in figure 1 
although the value of the exponent $n$ (equation 1) is greater than that found by experiments. Smith [1] shows that the Kutateladze equation represents the data at $0,5 \mathrm{~atm}$ reasonably well.

1.2 Peak nucleate boiling flux (P. N. B. F.). The maximum heat flux ortainable in nucleate boiling before passage to film boiling conditions is known as the peak nucleate boiling flux (P. N. B. F.). This flux is very important to know in the design of superconducting devices since most superconducting materials become normal under film-boiling conditions.

Experimental results of the P.N. B. F. for helium obtained on horizontal surfaces are very well correlated by the equation proposed by Kutateladze [7] and Chang and Snyder [9] as was shown recently by Lyon [2].

$$
\begin{aligned}
\frac{\text { P. N. B. F. }}{\lambda \rho_{\mathrm{v}}} & =K\left(\frac{\sigma g\left(\rho_{2}-\rho_{\mathrm{v}}\right)}{\rho v^{2}}\right)^{1 / 4} \\
\mathrm{~K} & =0,145\left(\frac{\rho_{2}+\rho_{\mathrm{v}}}{\rho_{2}}\right)^{1 / 2} .
\end{aligned}
$$

The P. N. B. F. as well as the shape of the nucleate boiling curve depend on a large number of variables not considered by empirical equations. Amongst the most important are : the nature of the heating surface, the hysteresis phenomenon, the roughness, pressure (temperature of the helium), surface orientation and geometry.

1.3 The NATURE OF THE HEATING SURFACE. The nature of the heating surface does not affect the nucleate boiling curve to a great extent but the value of the P.N.B. F. seems to be different for each surface. Table I indicate some literature values for horizontal surfaces. It is seen that the highest P. N. B. F. values are obtained with horizontal copper surfaces.

\section{TABLE I}

Influence of the nature of the surface on the P. N. B. F. Pressure: $1 \mathrm{~atm}$.

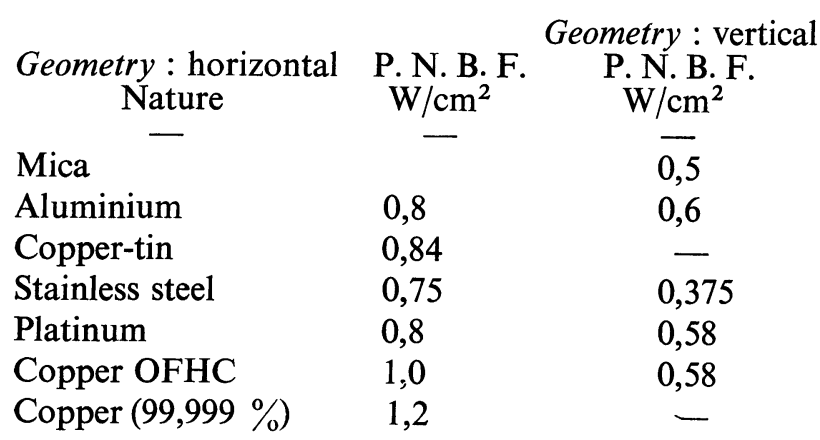

Cummings [3] and more recently Bowman [10] have proposed a correlation between the P.N. B. F. for helium at $1 \mathrm{~atm}$ and the physical property parameter of the solid used in unsteady state heat conduc- tion. More data are needed to confirm this correlation as has been shown by Lyon [6].

1.4 Surface COATINGs. - Cummings [3] reported that a coating of ice crystals enhances P.N. B. F. as much as $55 \%$. A recent study [5] on boiling in confined spaces has shown that when the heating surface is coated with epoxy resin ( 100 microns) P. N. B. F. values are increased by $35 \approx$. For very narrow channels the enhancement is somewhat less $(20 \%)$.

Lyon [6] has reported that dirty surfaces does not alter P.N.B.F. values but changes the boiling curve in the unstable boiling region.

1.5 Pressure. - Pressure influences the nucleate boiling characteristics to a large extent : the heat transfer coefficient increases with increasing pressure but the P. N. B. F. values are lowered. This same trend is predicted by the equation of Kutateladze [7] but the agreement with experimental data is disappointing, especially for values of $P / P c$ greater than 0,6 .

Klipping [11] has recently investigated natural convection from a cylinder at pressures above the critical (supercritical). The values of the heat transfer coefficient falls between that obtained for gaseous helium at $1 \mathrm{~atm}$ and nucleate boiling (1 atm).

1.6 THE HYSTERESIS PHENOMENON. - A number of cryogenic fluids exhibit a hysteresis phenomenon in the boiling curve [12], [13]: helium is not an exception. The hysteresis is due to a difference in the number of nucleating sites on increasing and decreasing flux : on increasing flux few sites are activated whereas on decreasing flux more sites remain active to much lower $\Delta T_{s}^{\prime}$. The hysteresis phenomenon has been illustrated by Thibault [4], Cummings [3] and Lyon [6]. Their results have been summarized by Smith [1].

1.7 Surface Roughness. - A rough surface seems to increase the heat transfer coefficient as was shown by Boissin [14] but has very little effect on the P. N. B. F. [6]. This is in agreement with the results of Berenson [15] for non-cryogenic fluids. Mueller [16] has recently developed an equation for calculating the nucleate boiling heat transfer of cryogens. This equation includes a roughness parameter. The equation has not been successful with He 1 data.

1.8 SuRface orientation. - Lyon [6] made a thorough study of surface orientation. The major effect is on the P. N. B. F. : the lowest P. N. B. F. values are obtained with the heating surface facing downward ; vertical surfaces exhibit P. N. B. F. values about 3 times higher and horizontal surfaces (facing upward) about 4 times higher at bath temperatures of $4,2 \circ \mathrm{K}$. At other bath temperatures the values are somewhat different but the general trend still holds. 
1.9 GeOMETRY. - The data shown in figure 1 suggest that convection might have an important role in pool boiling on vertical surfaces. An important consequence of convection is a decrease in P. N. B. F. with the height of the boiling surface, as is shown in figure 2. This result may be explained as follows : bubbles leaving the surface sets up a thermosiphon action. The bubbles leaving the lower portion of the heated surface are transported to the upper portion by the fluid motion decreasing the quality in this region. High heating surfaces are therefore inherently more unstable than short heating surfaces. The P. N. B. F. values indicated in figure 2 when extrapolated to zero heigh correspond to the values observed for horizontal surfaces.

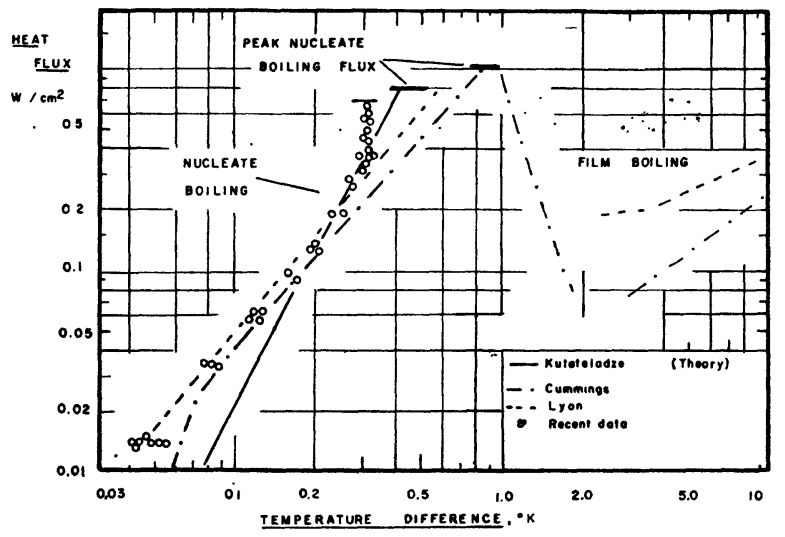

FIG. 1. - Pool boiling curve of helium 1 at 1 atm.

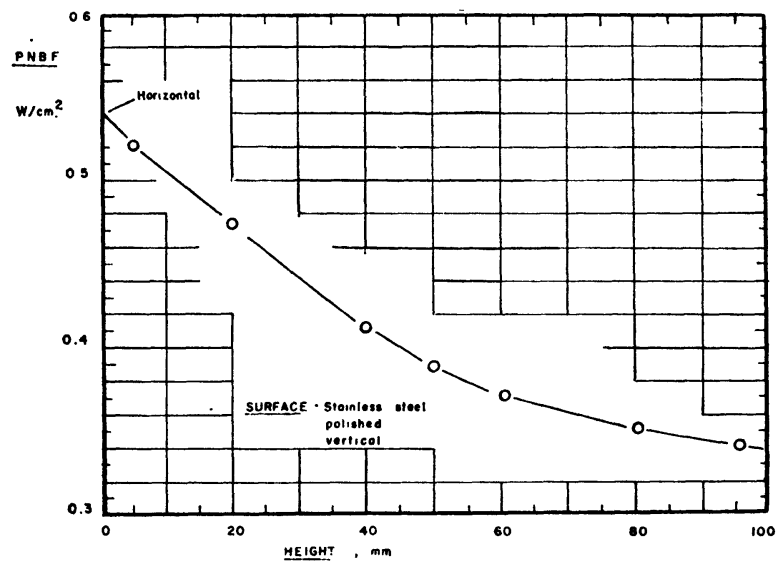

Fig. 2. - Influence of heating surface height on the peak nucleate boiling flux.

In most cryogenic devices the helium is allowed to circulate in confined spaces rather than in an open bath. These spaces take the form of channels, either circular on rectangular. The helium circulates by thermosiphon action.

There are been a number of studies in recent years to determine the heat transfer characteristics of helium 1 boiling under these conditions [17], [18], [19], [20]. These studies have shown that the helium flows induced by thermosiphon action are usually very high. Bubbles produced below are funnelled to the top of the channel and decrease the quality in this region. Thermal instabilities therefore originate at the top of these channels and move downward.

An equation has been proposed by Sydoriak and Roberts [17] to predict the P. N. B. F. for boiling of cryogens in confined channels. This equation has been tested by a number of authors [21], [22] but the agreement with experimental data is rather poor. A recent study has shown that the P. N. B. F. for boiling of helium in confined channels is an unique function of the length to diameter ratio of the channel. The diameter used is an equivalent diameter based on the heated perimeter.

Figure 3 shows the final correlation which represents data for a large number of geometries. The length to diameter ratio dependence is simular to that found for non-cryogens [23].

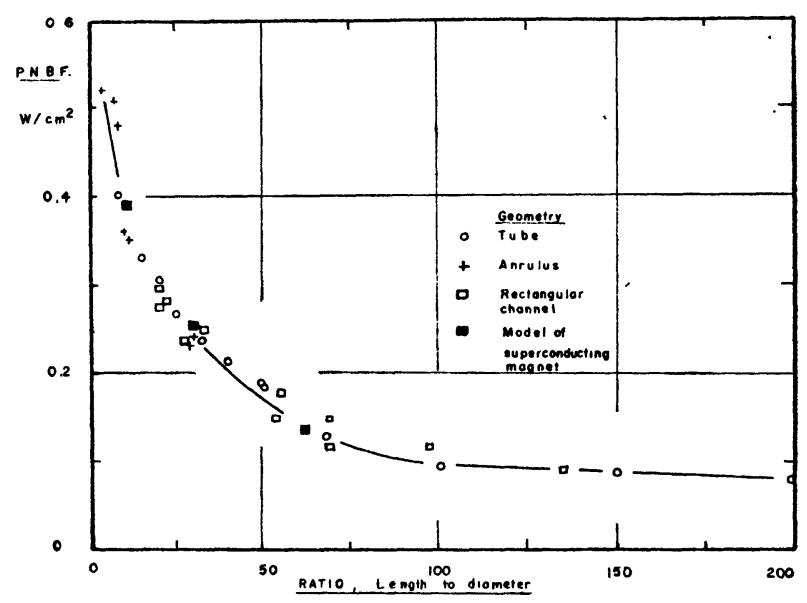

Fig. 3. - Peak nucleate boiling heat flux. Correlation.

2. Forced convection boiling. - This method of heat transfer is seldom used in practice since a circulating pump is required. It is probably the reason why very few data exist on forced convection boiling of helium.

Dorey [24] measured heat transfer to flat objects placed in a helium stream. This results agree fairly well with correlations obtained for non-cryogenic fluids.

De La Harpe [25] has measured heat transfer between a heated monel tube and helium liquid. The tube was helically coiled $3 \mathrm{~mm}$ diameter and five meters long. The data were very well presented by a modified Dittus-Boelter equation :

$$
\mathrm{Nu}=0,023\left(\mathrm{~N}_{\mathrm{He}}\right)^{0,85}\left(\mathrm{~N}_{\mathrm{pr}}\right)^{0,4}\left(\frac{\mathrm{D}}{\mathrm{D}_{\mathrm{He} \mathrm{liq}}}\right)^{0,1} .
$$

The pressure drop data are best presented by the « homogeneous model », as defined by Owens [26].

More recent data [27] on a vertical monel tube $2,12 \mathrm{~mm}$ in diameter and $296 \mathrm{~mm}$ long have clearly shown evidence of a flow boiling crisis as shown in figure 4 . Figure 4 shows that the flow crisis increases with increasing mass velocity, as to be expected. 


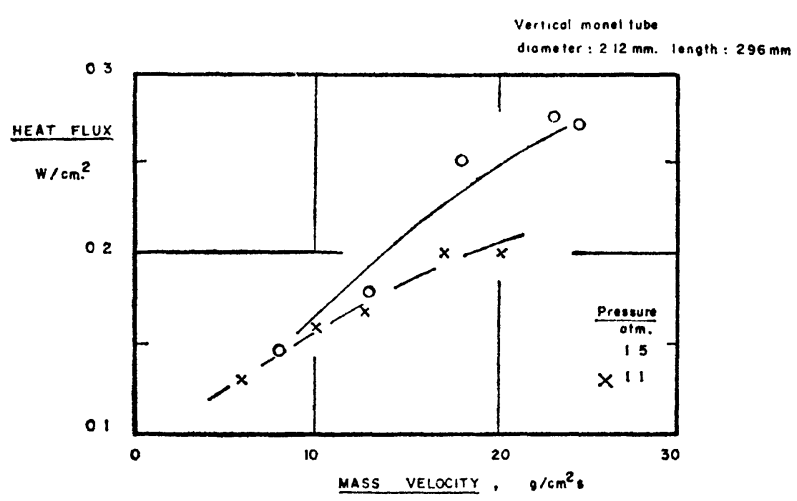

FIG. 4. - Influence of mass velocity on the flow crisis.

The heat transfer coefficients observed were very well presented by a correlation based on the Nusselt number ratio, $\mathrm{Nu}_{\text {exp }} / \mathrm{Nu}_{\text {calc }}$ against the MartinelliNelson $X_{t t}$ parameter. This type of correlation has been used for non-cryogens [28] and in a slightly different form for hydrogen [29]. The correlation is presented in figure 5 .

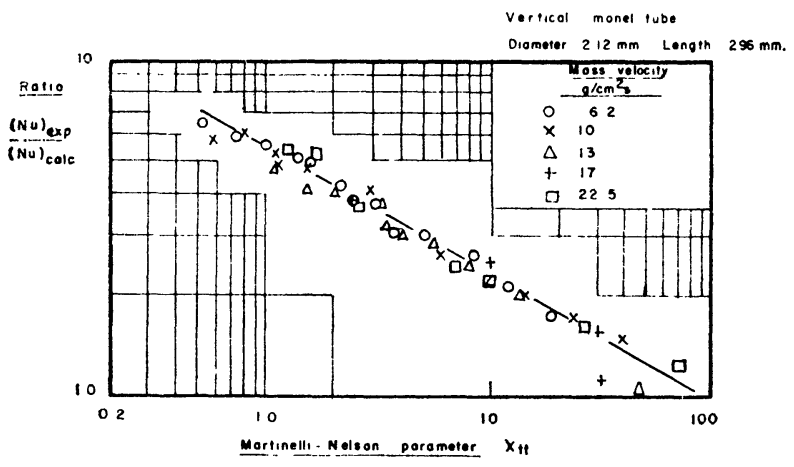

FIG. 5. - Heat transfer data correlation.

The forced convection boiling data for helium show that correlations used for non-cryogenic fluids seem to hold for helium. Obviously the constants used in the equations are different from one fluid to the other, nevertheless the same type of dependence on the different parameters is valid.

3. Forced convection heat transfer near the critical region. - The physical properties of helium near the critical point are especially suitable for heat transfer : the specific heat and thermal conductivity are both high in this region. These considerations with the advent of hollow conductors have led to the utilisation of high pressure helium in a number of design projects (for example the OMEGA project at C. E. R. N.).

There exist very few data on the heat transfer characteristics of helium in the critical region. Hay [30] has recently presented some data in the range 4 to $8{ }^{\circ} \mathrm{K}$ and 4 to $23 \mathrm{~atm}$. He found that heat transfer coefficients could be predicted by classical equations with a factor of about 2 for all conditions. A recent study [27] using heated monel tubes 1,5-2,12 and $3 \mathrm{~mm}$ in diamteer $450 \mathrm{~mm}$ long has confirmed that the heat transfer characteristics of helium are essentially gas-like in the near critical region. Some of the results are shown in figure 6 in which the heat transfer. coefficient are presented as a function of mass velocity. Figure 6 indicates that the heat transfer coefficient varies with mass velocity as :

$$
h \infty g^{0,8} .
$$

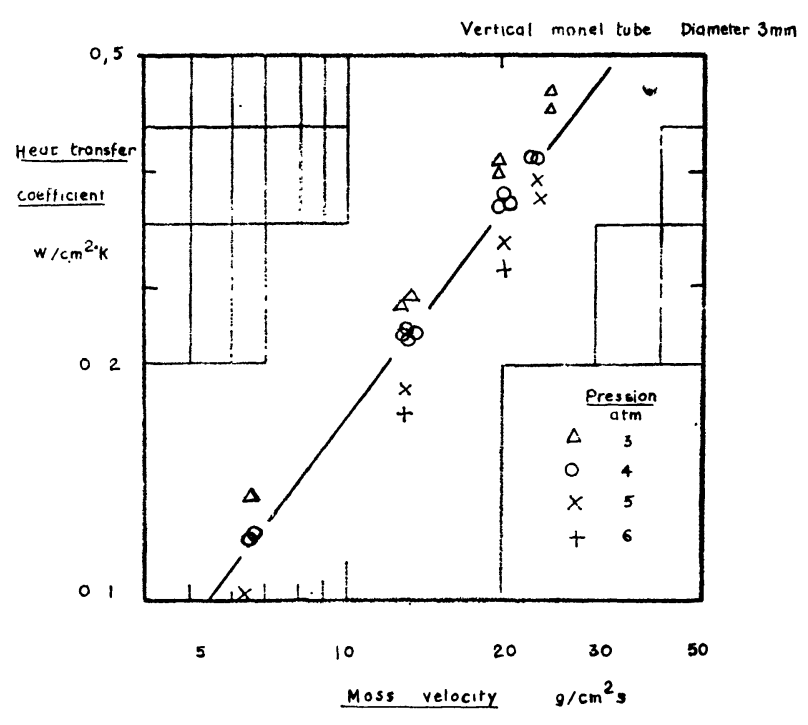

Fig. 6. - Heat transfer coefficients. Supercritical helium : small temperature differences.

Helium flow in the critical region is very unstable and it has been recommended that the pressure be kept at about $20 \mathrm{~atm}$ to avoid thermal oscillations. A recent study has shown that these oscillations may be eliminated by producing a high pressure drop at the inlet of the heated section [27].

The pressure drop of helium flowing in the nearcritical region corresponds to that calculated according to the classical equations.

4. Conclusions. - The pool boiling curve of helium 1 at atmospheric pressure is now fairly well established. It still remains to clarify the influence of certain parameters on the pool boiling characteristics. Of these the most important are the nature of the heating surface, the hysteresis phenomenon and helium pressure (especially for values of $P / P_{c}>0,6$ ).

The results obtained with helium boiling in confined spaces have shown that the P. N. B. F. values depend essentially on the ratio length to diameter of the channel.

Data on forced convection boiling is still not well known. There is some need to obtain more data for this mode of heat transfer.

Forced convection heat transfer in the near-critical region is still not sufficiently known. There is also a need to obtain data on the physical properties of helium in this region. 


\section{References}

[1] SMith (R. V.), Proceedings of the 1968 Brookhaven Summer Study on Superconducting Devices and Accelerators, 1968.

[2] LyON (D. N.), ( Advances in Cryogenic Engineering ), Vol. 10, 371, |Plenum Press, New [York, 1965.

[3] Cummings (R. D.), Sc. D. Thesis, Mass. Inst. Technol., Cambridge, nov. 1965.

[4] Thibault (J. J.), Roussel (J) and Faddi (E.), Bull, II R Annex 1965-2, 249 (Comm. I Meeting).

[5] Johannes (C.) and Mollard (J.), Paper to oc presented at Cryogenic Engineering Conference, June 1970.

[6] Lyon (D. N.), Chem. Eng. Progress Symposium Series, $1968,64,82$

[7] Kutateladze (S. S.), Atomic Energy Commission Translation 3770 (Techn. Info. Service, Oak Ridge Town).

[8] Brontari (E. G.) and Smith (R. V.), Advances in Cryogenic Engineering, Vol. 10, part 2, 371, Plenum Press, N. Y., 1965.

[9] Chang (Y. P.) and SNyder (N. W.), Chem. Eng. Progress Symposium, 1960, 56, 25.

[10] Bowman (H. F.), Sc. D. Thesis, Mass Inst. Technol. Cambridge, June 1968.

[11] Klipping (G.) and KutzneR (K.), Bull. II R Annex 5, 1966, 97.

[12] Bewilogua, Kroner (L.) and Wolf (G.), Cryogenics, $1966, \mathbf{b}, 36$

[13] Astruc (J. M.), Lacaze (A.), Perroud (P.) and WeIL (L.), Cryogenic Eng. Conf. Boulder, Colorado, June 13, 1966

[14] Boissin (J. C.), Thibault (J.-J.), Roussel (J.) and FADDI (E.), Advances in Cryogenic Engineering, 13, 607 (Plenum Press New York, 1967).
[15] Berenson (P. J.), Intern. J. heat and mass transfer, 1967, 5, 985 .

[16] Mueller (F. A.), Proc. 2nd Internat. Cryogenic Engineering Conference, 1968.

[17] SydoriaK (S. G.) and Roberts (J. R.), II R Meeting Comm. I Boulder (Colorado), 1966.

[18] Wilson (M. N.), II R Meeting, Comm. I Bonlder (Colorado), 1966.

[19] Whetstone (C. N.), Boom (R. W.), Advances in Cryogenic Engineering, 1967, 13, 68.

[20] Lehongre (S.), Boissin (J. C.), Johannes (C.) and De LA HaRpe (A.), Proc. 2nd Internat. Cryogenic Engineering Conference, 1968, 274.

[21] Lapin (A.), Totten (H. C.) and Wenzel (L. A.), A. I. Ch. E. Journal, 1965, 11, 503.

[22] Richards (R. J.), Steward (W. G.) and JaCobS (R. B.), N. B. S. TN 122, Bureau of Standards, Washington D. C. (oct. 1961).

[23] Shitsman (M. Ye.), USAEC Report AFC-tr-6290, 1963.

[24] Dorey (A. P.), Cryogenics, 1965, 5, 146.

[25] De La Harpe (A. S.), Lehongre (S.), Mollard (J.) and Johannes (C.), Proc. of the second Intern. Cryo. Eng. Conf., 1968, 274

[26] OWENS (W. L.), in International Developments in Heat Transfer, Pt II ASME, 1961.

[27] Johannes (C.), Paper to be presented at the Cryogenic Engineering Conference, June 1970.

[28] Tong (L. S.), " Boiling Heat Transfer in Two-phase flow ), John Wiley, New York, 1965.

[29] Hendricks (R. C.), Graham (R. W.), Hsu (Y. Y.), Medeiros (A. A.), Ars, J., 1967, 32.

[30] HAY (R. D.), Paper presented at Cryogenic Engineering Conference, June 1968. 